\title{
Analysis of Drought Characteristic in Sunit Prairie Based on Precipitation Anomaly Percentage during 2000-2015
}

\author{
Xiaodong Sun ${ }^{1}$, Guixiang $\mathrm{Liu}^{2 *}$, Yuhai $\mathrm{Bao}^{3}$, Xiaode Zhang ${ }^{2}$ \\ ${ }^{1}$ College of Geographical Science, Inner Mongolia Normal University, Hohhot, 010022, China \\ ${ }^{2}$ Institute of Grassland Research, Chinese Academy of Agricultural Sciences, Hohhot, 010010, \\ China
}

${ }^{3}$ Inner Mongolia Key Laboratory of Remote Sensing and Geographic Information System, Inner Mongolia Normal University, Hohhot, 010022, China

\section{基于降水距平百分率的 2000-2015 年苏尼特草 原干旱特征分析 \\ 孙晓东 ${ }^{1}$,刘桂香 ${ }^{2 *}$,包玉海 ${ }^{3}$, 张晓德 ${ }^{2}$ \\ ${ }^{1}$ 内蒙古师范大学 地理科学学院, 呼和浩特 010022 , 中国 \\ ${ }^{2}$ 中国农业科学院草原研究所, 呼和浩特 010010 , 中国 \\ ${ }^{3}$ 内蒙古师范大学 内蒙古自治区遥感与地理信息系统重点实验室, 呼和浩特 010022 , 中国}

\begin{abstract}
According to the monthly precipitation data collected from three meteorological stations $\mathrm{i}$ n Xilingol League from 2000 to 2015, annua 1 and seasonal drought features in Sunit prair ie for 16 years were detailed analysis by usi ng precipitation anomaly percentage from the drought frequency and the changing trends of drought. The results show that the freque ncy of annual precipitation had increased ten dency in Sunit prairie from 2000 to 2015, th e precipitation tendency was 6077/10a; Preci pitation showed a significantly decreasing tre nds in spring, summer and winter, and the $\mathrm{i}$ ncreasing trend of precipitation in autumn; $\mathrm{F}$ or annual and seasonal scale, the frequency of light drought was higher.
\end{abstract}

Keywords: Sunit Prairie; Drought; Precipitation anomaly percentage

*通讯作者: 刘桂香, Email:liugx804@163.com.

\section{摘要}

利用 2000-2015 年锡林郭勒盟 3 个气象站点逐 月降水量资料, 采用降水距平百分率, 从干旱 频率和干旱变化趋势率两个方面对 16 年间苏 尼特草原年际和季节干旱特征进行详细分析。 研究结果表明：2000-2015 年苏尼特草原逐年 降水量有增加趋势, 苏尼特草原降水量变化倾 向率为 6.77/10a; 春季、夏季和冬季降水量为 降低趋势, 秋季降水量为增加趋势; 年际和季 节尺度轻旱频率均较高。

关键词: 苏尼特草原、干旱、降水距平百分率

\section{1. 引言}

随着全球气温的不断上升和中国地区暖冬年 份的连续出现, 中国北方地区呈现干旱化趋势 日益显著[1-3]。干旱是指在一定区域的较短时 期内, 因降水明显少于正常状态而导致水资源 减少、影响植物正常生长的一种自然现象 [4]。 干旱是对生产、生活、生态影响最严重的自然 灾害之一[5]。据 Obasi 统计, 在各类自然灾害 造成的总损失中, 气象灾害引起的损失约占 
$85 \%$, 而干早又占气象灾害损失的 $50 \%$ 左右 $[6]$ 每年因干旱造成的全球经济损失高达 60-80 亿 美元, 干旱灾害远远超过其他气象灾害 [7-8]。 锡林郭勒盟是我国最典型的草原分布区, 这一 地区是全球变化响应的敏感带, 受干旱影响比 较大 $[9]$ 。苏尼特草原是锡林郭勒草原的一部分, 是荒漠草原的代表性区域, 是典型草原向荒漠 化草原过度的草原生态系统。由于苏尼特草原 属于大陆性气候区, 降水少且分布不均, 蒸发 量大等气候特点, 决定苏尼特草原极易形成干 旱灾害。目前, 干旱灾害监测指标主要基于气 象数据和遥感数据, 干旱灾害监测指标主要分 两大类: 传统干旱灾害监测指标和遥感干旱灾 害监测指数 [10]。传统干旱灾害监测[11-13]指 标有距平百分率 (Percent of Normal)、帕默尔 指数 (Palmer Drought Severity Index, PDSI)、 标准降水指数 [14]（Standardized Precipitation Index, SPI)、作物湿度指数 (Crop Moisture Index, CMI) 等[15]。遥感干旱灾害监测指数 有基于可见光/近红外数据的植被状态指数 (Vegetation Condition Index, VCI)、基于热红 外数据的温度状态指数 (Temperature Condition Index, TCI)、热惯量指数等[15-16]。 本文选用传统干旱灾害监测指标, 即降水距平 百分率方法, 从不同时间尺度对苏尼特草原进 行干旱研究, 为草原的保护、开发利用和建设、 畜牧业生产的大力发展, 乃至社会发展、环境 保护提供科学依据。

\section{2. 研究区概况}

苏尼特草原位于北纬 $41^{\circ} 55^{\prime} \sim 45^{\circ} 15^{\prime}$, 东经 $111^{\circ} 08^{\prime} \sim 115^{\circ} 12^{\prime}$, 地处内蒙古自治区中部, 锡 林郭勒盟西部, 北与蒙古人民共和国接壤, 南 与正镶白旗、正蓝旗、乌兰察布市察右后旗、 商都县交界, 西邻乌兰察布市四子王旗, 东接 阿巴嘎旗。其国境线长达 400 多千米, 面积达 6 万多平方千米。苏尼特草原涵盖三个旗县市 (区), 分别是苏尼特左旗、苏尼特右旗和二 连浩特市[17]。苏尼特草原是温带大陆性气候, 其气候多受蒙古高压的影响。该研究区域主要 的气候特点是风大、干旱和寒冷。年均气温 3-5 ${ }^{\circ} \mathrm{C}$; 降水量多集中在 6-9 月, 年降水量在 150-200 mm; 年蒸发量远超过降水量, 可达 15-20 倍以上; 风速超过 $4 \mathrm{~m} / \mathrm{s}$, 湿润度为
0.13-0.3。其草地植被类型主要是荒漠草原, 该草原的建群种是由旱生多年生丛生小禾草 为主, 并有一定数量旱生、强旱生小半灌木、 灌木参与组成的草地类型。

\section{3. 数据与方法}

\section{1. 数据来源}

本文选取锡林浩特盟 3 个气象观测站点 (二连 浩特市、苏尼特左旗、苏尼特右旗) 2000-2015 年逐月降水量资料, 采用降水距平百分率方法, 分别计算降水年际和季节 [18] (每年阳历 $3 \sim 5$ 月为春季、 $6 \sim 8$ 月为夏季、9 $\sim 11$ 月为秋季、 12 次年 2 月为冬季) 变化, 采用降水距平百 分率干旱等级评价指标, 分析了不同等级干旱 特征。

\section{2. 研究方法}

\subsection{1. 降水距平百分率}

降水距平百分率是干旱灾害常用的指标之一, 降水指标能够反映干旱的发生程度, 它是指某 时段的降水量与常年同期降水量相比的百分 率, 是表征某段降水量较常年值偏多或偏少的 程度, 能够直观反映降水异常引起的干旱 [19-21]。计算公式如下:

$$
P_{a}=\frac{P-\bar{P}}{\bar{P}} \times 100 \% \quad \bar{p}=\frac{1}{n} \sum_{i=1}^{n} P_{i}
$$

式中: $\mathrm{P}_{\mathrm{a}}$ 为降水距平百分率, $\% ; \mathrm{P}$ 为计 算时段内降水量, $m m ; \bar{P}$ 为多年同期平均降水 量; $P_{i}$ 为某时段的降水量, $\mathrm{mm} ; \mathrm{n}$ 为年数; $\mathrm{i}=1,2, \ldots, \mathrm{n}$ 。

\subsection{2. 干早等级标准}

本文采用国家气象干旱等级标准, 干旱程度等 级划分为 5 级, 分别是无旱、轻旱、中旱、重 旱和特旱 (见表 1 )。

\section{4. 降水特征分析}

\section{1. 年际变化特征}

利用 2000-2015 年苏尼特草原 (二连浩特市、 苏尼特左旗、苏尼特右旗) 逐月降水资料, 统 
Risk Analysis and Crisis Response in Big Data Era (RAC-16)

计得出年际降水变化情况, 由图 1 可以看出, 2003 年降水量最大 $(230.77 \mathrm{~mm}) ; 2005$ 年降 水量最小 $(78.70 \mathrm{~mm})$; 降水年际变化明显, 平均变化幅度为 $150.41 \mathrm{~mm}$, 其中 $2011 \sim 2012$
年间变化幅度最大 $(101.67 \mathrm{~mm}), 2006 \sim 2007$ 年间变化幅度最小 $(2.20 \mathrm{~mm})$ 。该研究区域降 水量变化倾向率为 $6.77 / 10 \mathrm{a}$, 说明该研究区域 在 2000-2015 年间降水量有增加趋势。

表 1. 降水量距平百分率气象干旱等级划分表

\begin{tabular}{cccc}
\hline \multirow{2}{*}{ 等级 } & \multirow{2}{*}{ 类型 } & \multicolumn{2}{c}{ 降水距平百分率 $/ \%$} \\
\cline { 3 - 4 } & & 年尺度 & 季尺度 \\
\hline 1 & 无早 & $-15<\mathrm{Pa}$ & $-25<\mathrm{Pa}$ \\
2 & 轻早 & $-30<\mathrm{Pa} \leq-15$ & $-50<\mathrm{Pa} \leq-25$ \\
3 & 中旱 & $-40<\mathrm{Pa} \leq-30$ & $-70<\mathrm{Pa} \leq-50$ \\
4 & 重旱 & $-45<\mathrm{Pa} \leq-40$ & $-80<\mathrm{Pa} \leq-70$ \\
5 & 特早 & $\mathrm{Pa} \leq-45$ & $\mathrm{~Pa} \leq-80$ \\
\hline
\end{tabular}

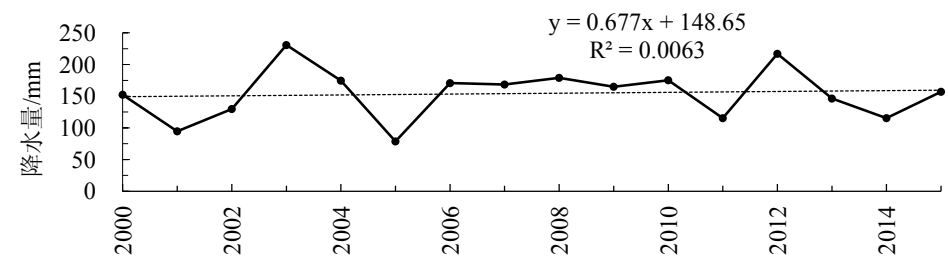

年份

图 1.2000-2015 年苏尼特草原年降水量变化

\section{2.季节变化特征}

利用 2000-2015 年苏尼特草原（二连浩特市、 苏尼特左旗、苏尼特右旗）逐月降水资料，统 计得出季节降水变化情况, 由图 2 可以看出, 春季降水量变化倾向率为-1.592/10a, 夏季降 水量变化倾向率为 $-9.665 / 10 \mathrm{a}$, 秋季降水量变 化倾向率为 $15.733 / 10 \mathrm{a}$, 冬季降水量变化倾向 率为-0.128/10a。综上所述, 在 2000-2015 年间 苏尼特草原春季、夏季和冬季降水量为降低趋 势, 秋季降水量为增加趋势, 且该区域春季、 夏季和冬季都有不同程度的干旱化趋势。

\section{5. 研究区干旱特征分析}

\section{1. 干早年际变化特征}

基于苏尼特草原年尺度 $P_{\mathrm{a}}$ 序列（图 3）表明, 2000-2015 年间干旱时有发生, 16 年间共出现 了 5 次干旱事件, 平均约 3 年发生一次干旱, 干旱年份有 2001 年、 2002 年、 2005 年、2011 年和 2014 年, 其中 2002 年、 2011 年和 2014 年为轻旱; 2001 年为中旱; 2005 年为重旱。
苏尼特草原干旱的总频率为 $31.25 \%$, 其中轻 旱频率最高, 为 $18.75 \%$; 中旱频率和重旱频 率均为 $6.25 \%$ 。说明 16 年中有 5 年发生不同 等级的干旱, 其中轻旱发生的频率较高, 中旱 和重旱发生的频率较低。

\section{2. 干旱季节变化特征}

春季, 基于苏尼特草原季节尺度 $\mathrm{Pa}$ 序列（图 4) 表明, 在 16 年间, 发生春旱年份有 4 年, 分别是 2001 年、2004 年、2006 年和 2013 年。 其中 2001 年为中旱; 2013 年为重旱; 其余年 份为轻旱。研究结果表明, 该研究区域平均 4 年发生一次春旱, 春旱发生的年份中, 轻旱发 生频率较高, 中旱和重旱发生频率较低。

夏季, 基于苏尼特草原季节尺度 $\mathrm{Pa}$ 序列 (图 4) 表明, 在 16 年间, 发生夏旱年份有 6 年, 分别为有 2001 年、 2005 年、 2010 年、 2011 年、 2014 年和 2015 年。其中 2005 年为中旱; 其余年份为轻旱。研究结果表明, 该研究区域 夏早发生的年份中, 轻旱发生频率较高, 为 $31.25 \%$ 。 
Risk Analysis and Crisis Response in Big Data Era (RAC-16)
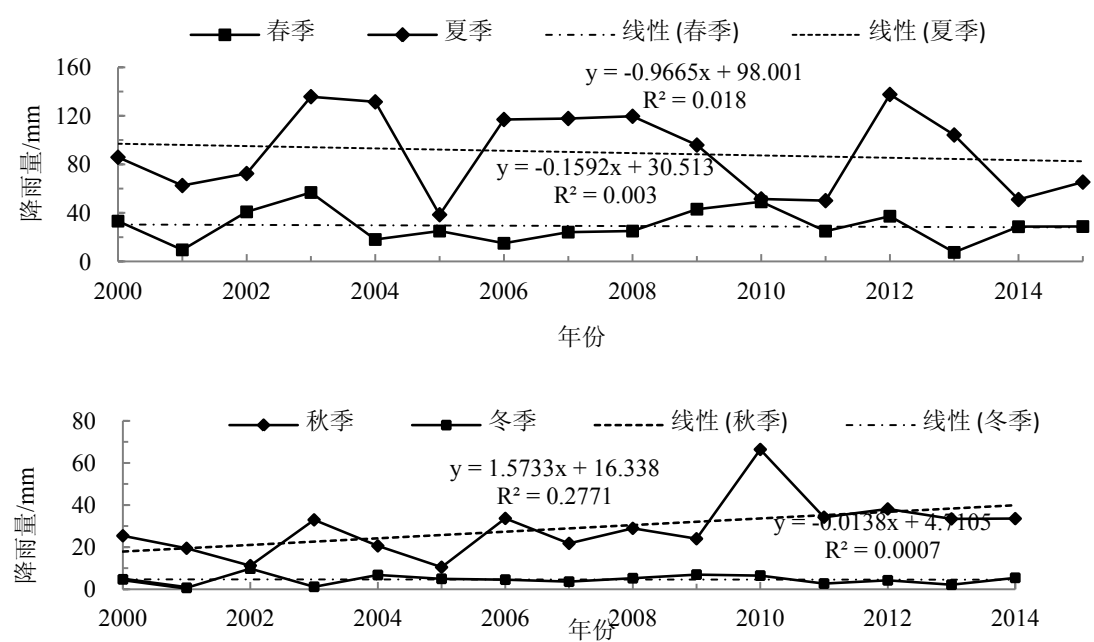

图 2. 2000-2015 年苏尼特草原季节降水量变化

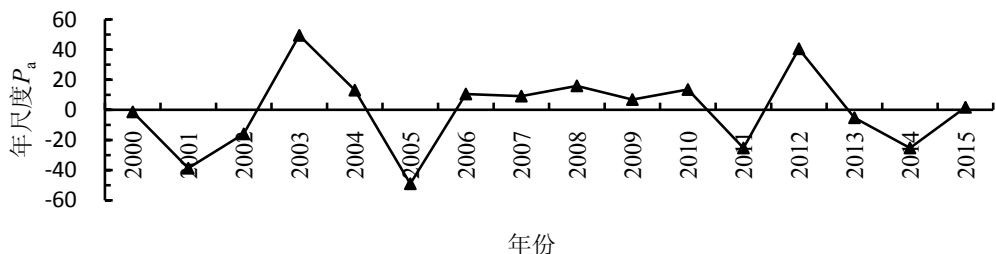

图 3. 苏尼特草原年尺度 Pa 序列

秋季，基于苏尼特草原季节尺度 $\mathrm{Pa}$ 序列 （图 4) 表明, 在 16 年间, 发生秋旱年份有 5 年, 分别为 2001 年、 2002 年、 2004 年、 2005 年和 2007 年。其中 2002 年和 2005 年为中旱; 其余年份为轻旱。研究结果表明, 该研究区域 秋旱发生的年份中, 轻旱发生频率较高, 中旱 发生频率较低。

冬季, 基于苏尼特草原季节尺度 $\mathrm{Pa}$ 序列 （图 4) 表明, 在 16 年间, 发生冬旱年份有 4 年，分别为 2001 年、 2003 年、 2011 年和 2013 年。其中 2011 年为轻旱; 2013 年为中旱; 其 余年份为轻旱。研究结果表明, 该研究区域冬 旱发生的年份中, 轻旱发生频率较高。

综合季节干旱出现年份可以看出, 2001 年出现了四季连旱; 夏秋连旱出现的年份是 2005 年。夏季轻旱发生的频率较高; 冬季重 旱发生的频率较高。总体来说, 季节干旱尺度
和年尺度对干旱的研究基本一致, 该研究区域 均未发生特旱, 且季节尺度干旱的频率和年尺 度干旱的频率也基本一致。季节尺度干旱频率 略小于年尺度干旱频率, 季节尺度轻旱频率略 小于年尺度, 且两种尺度中轻旱频率均最高。

6. 结论

通过分析苏尼特草原 2000-2015 年际和季节干 旱的频率和变化趋势, 得出以下结论:

利用 2000-2015 年苏尼特草原逐月降水资 料, 应用降水距平百分率干旱指标, 对降水量 与干旱特征进行年际和季节特征分析, 得出年 际降水变化呈增加趋势, 降水量变化趋势率为 $6.77 / 10 \mathrm{a}$ 。季节降水变化中春季、夏季和冬季 降水量为降低趋势, 秋季降水量为增加趋势。 总体来看, 该研究区域二十世纪以后降水量有 

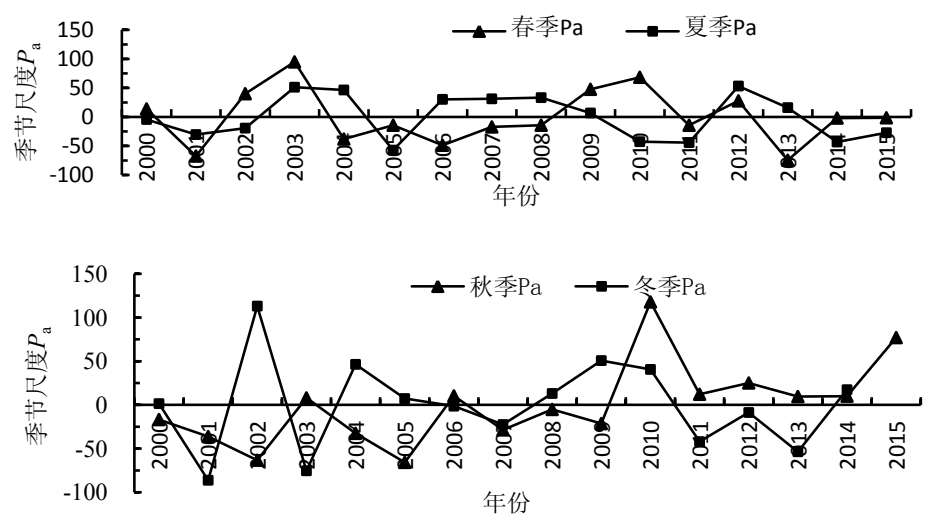

图 4. 苏尼特草原季节尺度 $\mathrm{Pa}$ 序列

所增加, 干旱化趋势有所减缓。年尺度干旱约 3 年一次, 季节尺度干旱约 3 或 4 年一次, 干 旱等级主要为轻旱。

本研究只考虑降水量单一指标对干旱的 影响, 无法反应出风速、气温、温度等因子对 形成干旱的作用, 这些不足需要在日后的研究 中得到进一步的完善, 为干旱监测和评估工作 提供更为客观合理的方法。

\section{Acknowledgements}

This study was supported by Chinese Academy of Agricultural Sciences Innovation Proje ct grassland abiotic Disaster Prevention and Mitigation Team (No.CAAS-ASTIP-IGR2015 -04), and the Graduate Research Innovation Foundation of Inner Mongolia Normal Unive rsity (No.CXJJS15098).

Corresponding author: Guixiang Liu, Email: liugx804@163.com.

\section{致谢}

本研究得到了中国农业科学院创新工程草原 非生物灾害防灾减灾团队 (CAAS-ASTIP-IGR 2015-04), 内蒙古师范大学硕士研究生科研创 新基金项目（CXJJS15098）的资助。

\section{参考文献}

[1] 张庆云. 1880 年以来华北降水及水资源的 变化. 高原气象, 1999, 18(4):486-495.

[2] Fu C, Jiang Z, Guan Z, et al. Aridity Trend in
Northern China. Regional Climate Studies, 2008:155-217.

[3] Ma Z, Fu C. Interannual characteristics of the surface hydrological variables over the arid and semi-arid areas of northern China. Global \& Planetary Change, 2003, 37(3):189-200.

[4] Rulinda C M, Dilo A, Bijker W, et al. Characterising and quantifying vegetative drought in East Africa using fuzzy modelling and NDVI data. Journal of Arid Environments, 2012, 78(3):169-178.

[5] 吴琼, 赵春雨, 王大钧, 等. 1951-2014 年辽 宁省气象干旱时空特征分析. 干旱区资 源与环境, 2016(3): 19-22.

[6] Obasi G O P. WMO's role in the international decade for natural disaster reduction. Bulletin of the American Meteorological Society, 1994, 75(9): 1655-1661.

[7] Wilhite D A. Drought as a natural hazard : Concepts and definitions. Drought A Global Assessment, 2000, 1:3-18.

[8] 张巧风, 刘桂香, 于红博, 等. 基于标准化 降水指数的锡林郭勒盟干旱特征分析. 自然灾害学报, 2015(5):119-128.

[9] 李春兰, 俞立中, 张继权,等. 基于 SPI 的 1961-2011 年锡林郭勒盟气象干旱时空特 征分析. 风险分析和危机反应中的信息 技术, 黄崇福, 包玉海, 赵思健编. 巴黎: Atlantis 出版社, pp.501-506, 2014. 
Risk Analysis and Crisis Response in Big Data Era (RAC-16)

[10] 那音太. 内蒙古干早遥感监测研究进展. 风险分析和危机反应中的信息技术, 黄崇 福, 包玉海, 赵思健编. 巴黎: Atlantis 出 版社, pp.690-693, 2014.

[11] 王玲玲, 张友静, 余远见, 等. 遥感旱情监 测方法的比较与分析。遥感信息, 2010(5):49-53.

[12] 胡红武, 胡梅, 龙玲,等. 区域干旱遥感监 测研究综述。安徽农业科学, 2008, 36(33):14817-14819.

[13] 邹旭恺, 张强, 王有民,等. 干旱指标研究 进展及中美两国国家级干旱监测.气象, 2005, 31(7):6-9.

[14] Yi Z, Liu G, Yu F, et al. The Combustible Materials Remote Sensing Ration Calculation and Fire Risk Dynamic. Journal of Risk Analysis and Crisis Response, 2011, 1(1):65-74.

[15] 卓义. 基于遥感与 GIS 技术的内蒙古东 部草原地区干旱灾害监测, 评估研究. 中 国农业科学院博士学位论文, 2011

[16] 郭虎, 王瑛, 王芳. 旱灾灾情监测中的遥 感应用综述，遥感技术与应用，2008， 23(1):111-116.

[17] 李景平. 苏尼特荒漠草原景观动态研究 [D]. 中国农业科学院, 2007.

[18] 包姝芬, 马志宪, 崔学明. 近 50 年锡林郭 勒盟的气候变化特征分析. 内蒙古农业 大学学报：自然科学版，2011, 32(3): $157-160$

[19] 王富强, 王雷. 基于降水距平百分率的河 南省干旱特征分析. 中国农村水利水电, 2014(12):84-88.

[20] 格桑，苏雪燕，普布卓玛. 降水距平百分 率在西藏干旱判定中的验证. 西藏科技, 2009(2):60-62.

[21] 陈少勇, 郭俊瑞, 吴超. 基于降水量距平 百分率的中国西南和华南地区的冬早特 征. 自然灾害学报, 2015(01):23-31. 